\title{
NEWCOMERS’ INTERNATIONAL EXPERIENCE BACKGROUNDS AND \\ CONTRIBUTIONS TO TEAM PERFORMANCE
}

\begin{abstract}
This paper examines the relationship between new team members' international experience backgrounds and subsequent contributions to team performance at the first year of team membership. It is argued, that individuals' experiential backgrounds can range from narrow careers in single national contexts to broad careers in multiple international settings, with different developmental effects on newcomers' knowledge, competencies, and subsequent potentials to successfully contribute to team performance. Importantly, the experiential composition of the entire team moderates these relationships in such a way that newcomers' broad international backgrounds constitute valuable inputs of new knowledge and perspectives in experientially homogeneous and long tenured teams. A set of hypotheses was tested on a longitudinal multilevel dataset from seven consecutive seasons of German Bundesliga football (2005-2012) and provided support for our predictions. Implications of these findings are discussed together with future research directions.
\end{abstract}




\section{INTRODUCTION}

As a response to the dynamics of a globalized competitive environment, organizations increasingly rely on teams to take advantage of team members’ knowledge and expertise (e.g. Bunderson, 2003a). Both from a practitioner's and a scholar’s perspective, individuals’ prior experiences thereby serve as an expedient proxy for the knowledge, expertise, and competencies held by team members (cf. Tesluk \& Jacobs, 1998; Quinones, Ford, \& Teachout, 1995). Organizations often hire on the basis of prior work experience (Rynes, Orlitzky, \& Bretz, 1997; Dokko, Wilk, \& Rothbard, 2009), and researchers have focused on educational (e.g. Dahlin, Weingart, \& Hinds, 2005), functional (e.g. Bunderson \& Sutcliffe, 2002), or international experiences of team members (Carpenter, Sanders, \& Gregersen, 2000) as determinants of team processes and outcomes. A basic premise underlying theory and research on experiential team composition is that team members with different experiential backgrounds bring different knowledge and perspectives to their teams (Bunderson, 2003b). Along these lines, individuals' careers and experience backgrounds have been described as important resources that teams can draw upon (Bunderson, 2003b; Kor, 2003; Castanias \& Helfat, 1991).

Meanwhile, individuals’ career trajectories have become increasingly independent of single employment settings and mobile across the boundaries of teams, organizations, and countries (Sullivan \& Baruch, 2009; Hall, 1996; Arthur \& Rousseau, 1996). With this, team composition has become a dynamic process, where individual members move on and off teams for a variety of reasons such as turnover, promotions, or changing task demands that require an adjustment of a team's knowledge configuration (Mathieu, Maynard, Rapp, \& Gilson, 2008). Frequent change in team composition has led to a need to understand the role of newcomers in more detail. Specifically, competitive pressures require managers and researchers to better understand which individuals will benefit a team, i.e. which newcomers are likely to effectively contribute to team performance. 
The general logic of experiential team composition suggests that newcomers' experience backgrounds have shaped their knowledge and perspectives brought to a team, and should consequently influence newcomers' likelihood for contributing to team performance. At the same time, the growing importance of international experiences has been recognized as a characteristic of contemporary careers (Gregersen, Morrison, \& Black, 1998). Research on expatriates suggests that international experiences have developmental effects on individuals' knowledge and skills (e.g. Cappellen \& Jannssens, 2005; Suutari, 2003), as international environments lead to situations of intense experiential learning (Jokinen, 2010). International experiences of team members have thus been described as rare, valuable, and hard to imitate, holding the potential to create competitive advantages (Carpenter, Sanders, \& Gregersen, 2000). Such insights from research on international careers and experience would thus suggest that teams benefit from internationally experienced newcomers.

However, as teams and newcomers might also face difficulties to integrate these potentials (Bauer, Bodner, Erdogan, Truxillo, \& Tucker, 2007), the expected effects on subsequent contributions to team performance may be difficult to predict. How international experience backgrounds benefit or hinder newcomers' performance contributions has not been systematically addressed. This is the primary aim of this paper. Further, prior research has brought forward that team processes and performance are dependent on a team's experiential configuration. Composition in terms of average team tenure (e.g. Berman, Down, \& Hill, 2002; Humphrey, Morgeson, \& Mannor, 2009) or diversity in experiences (e.g. Bunderson \& Sutcliffe, 2002) influences how team members interact, cooperate, and take advantage of their individual experiential assets. Newcomers might thus find new team environments that allow for own contributions to varying degrees. As a second purpose, this paper therefore examines how the performance contributions of newcomers depend on the experiential composition of the joined team. 
The paper continues as follows. First, the complexity of possible benefits and potential problems associated with newcomers as a source of new and diverse knowledge is highlighted from a theoretical perspective. Subsequently, the paper develops a set of hypotheses on how and under what conditions newcomers are more likely to contribute to team performance. Then, research setting, data, and methods are described, followed by a presentation of the findings. To conclude, the paper elaborates on these findings, and discusses implications and future research directions.

\section{THEORY AND HYPOTHESES}

Newcomers have been described as a source of new knowledge in teams and organizations that may enable innovation, learning, and performance (e.g. Almeida, Dokko, \& Rosenkopf, 2003; Rao \& Drazin, 2002; Perretti \& Negro, 2007). March (1991) analyzed existing team members' and newcomers' influences on new organizational knowledge in a simulation model of personnel turnover, thereby comparing existing team members' and newcomers' contributions: Existing team members, on average are more knowledgeable, but what they know is often redundant with the knowledge already reflected in the organization. Newcomers, on the other hand are often less knowledgeable, but are more likely to contribute to the creation of new knowledge, as what they know is less redundant with the knowledge already available. With this, newcomers can diversify a group's knowledge base via the infusion of new experiences, perspectives, and information (e.g. Levine \& Choi, 2004; Levine, Choi, \& Moreland, 2003; Staw, 1980).

Besides this, however, newcomers have also been associated with substantial problems for team processes and performance: New team members often lack the skills necessary to function in a specific team setting, thus undermining the overall team's ability to perform (Choi \& Thompson, 2005). Socialization refers to the process by which newcomers make a 
transition from team outsiders to being team insiders (Bauer et al., 2007; Van Maanen \& Schein, 1979). This process of socialization or integration can be costly and time-consuming (cf. Ostroff \& Kozlowski, 1992) as newcomer's need to learn about their new environment. When joining a new team setting, newcomers may experience a liability of foreignness (Perretti \& Negro, 2007), and face disadvantages of stereotyping, and marginalization by existing team members (Jackson, Stone, \& Alvarez, 1993). As a result, newcomers may face problems to interact and cooperate with the existing team and bring their potentially advantageous knowledge and expertise to bear.

The preceding theoretical viewpoints suggest that newcomers are associated with both potential benefits of providing new knowledge inputs as well as difficulties to incorporate these inputs in a new team. With the aim of developing a better understanding of newcomers' impact on team functioning and performance, researchers have further studied new team members in different team settings to examine the conditions under which benefits or problems will predominantly manifest (Bauer et al., 2007; Jackson, et al., 1993). Recent suggests that, in order to gain a better understanding on the effects of newcomers on team functioning and performance, future studies should consider through which experience related attributes and under what conditions newcomers are more likely to have a positive contribution to team performance (Perretti \& Negro, 2007). Based on this premise, the paper builds on these arguments to examine the influence of internationally experienced newcomers. While scholars have described international experiences as valuable resources that teams draw upon (e.g. Carpenter, Sanders, \& Gregersen, 2000), past research has also highlighted problems associated with taking full advantage of internationally experienced individuals’ knowledge and competences (e.g. Dickmann \& Harris, 2005; Vermond, 2001). International experience backgrounds of newcomers thus appear as a highly relevant subject to study against the preceding theoretical background. 


\section{Broad and narrow international backgrounds}

Recently, scholars have turned their attention to examining the question of what kind of knowledge and expertise individuals actually develop when gaining international experience (e.g. Suutari \& Mäkelä, 2007; Suutari, 2003; Eby, Butts, \& Lockwood, 2003). Generally speaking, this literature argues that international experiences create intense learning situations with developmental effects on knowledge and competencies as individuals are confronted with high responsibilities and encounter cross-cultural differences (Dickmann \& Doherty, 2008). At the same time, also more context-specific knowledge and competencies are developed during international assignments. As contextual factors are considered to have a direct influence on work experiences and its outcomes (Tesluk \& Jacobs, 1998; Bhagat, Kedia, Harveston, \& Trianidis, 2002), international experiences also reflect an individual's type of knowledge or perspective about country-related, contextual peculiarities. With this, international experiences may also result in more specific knowledge and skills that are less transferable across contexts because of a lack of applicability or compatibility of the acquired knowledge in a new context (Dickmann \& Harris, 2005; Bonache, Brewster, \& Sutari, 2001).

Further, international careers may differ to the extent to which they span a narrow set of few of single country assignments or a relatively broad range of multiple international settings. Importantly, prior research on internationally mobile individuals suggests that narrow or broad career backgrounds have distinctive developmental effects on acquired knowledge and competencies (Jokinen, 2010). Accordingly, experiences acquired in a limited number of international contexts have deepening effects, leading to relatively specialized and context-dependent knowledge and competencies. On the other hand, more dispersed careers across multiple international contexts have widening effects, leading to the development of broader and more generalist knowledge and competencies. 
These insights come in parallel with conceptualizations of individuals’ backgrounds in other experiential domains, such as functional or educational backgrounds (e.g. Bunderson \& Sutcliffe, 2002; Dahlin \& Weingart, \& Hinds, 2005). Bunderson and Sutcliffe (2002), for instance, focused on the degree to which individuals' backgrounds are characterized by intrapersonal diversity, i.e. the extent to which an individual is considered a narrow functional specialist with experience in a limited range of functional domains, or a broad generalist whose experiences span a wide range of functions. Building on social categorization theory (Tajfel, 1981; Turner, 1982), Bunderson and Sutcliffe (2002) proposed that intrapersonal experiential diversity facilitates the sharing of information with other team members. An individual with experiences from several functional areas will be less likely to view others and be perceived by others in stereotyped and biased ways, whereby communication, cohesion, and collaborative problem solving is facilitated.

These findings from earlier work on individuals’ experience backgrounds may serve as a basis to relate the relative breadth in newcomers' international backgrounds to expected contributions to team performance. When joining a team, newcomers may face the disadvantage of being perceived by existing team members in a stereotyped and biased way, resulting in problems to interact and cooperate, and bring their potentially beneficial external knowledge to bear (Jackson, Stone, \& Alvarez, 1993). Newcomers with broad experiential backgrounds are less susceptible to experientially grounded stereotyping and in-group/outgroup biases because they are less strongly identified with single experiential areas. Broad backgrounds allow newcomers to claim membership in a variety of experiential domains, facilitating the interaction and cooperation with other team members (Bunderson \& Sutcliffe, 2002).

Newcomers with relatively narrow experiential backgrounds, to the contrary, are likely to face higher barriers to successful interaction and cooperation. Newcomers with narrow careers have developed deep and specialized knowledge that is potentially less transferable 
across contexts because of a lack of applicability or compatibility in new contexts (Dickmann \& Harris, 2005; Bonache, Brewster, \& Sutari, 2001). Such a specializing effect increasing the context-dependence of acquired knowledge is less dominating for individuals pursuing more globalized careers in multiple contexts, whose knowledge and competencies, although less deep and specialized, are thus considered to be better transportable across contexts. In addition, newcomers with global prior careers have been familiarized with various contextual conditions and have gone through several adjustment processes in the past (Suutari, 2003; Suutari \& Mäkelä, 2007). Prior socialization and adjustment experiences are expected to facilitate the integration in a new team, enabling newcomers with broad international backgrounds to fast and effectively contribute to team performance.

In sum, it is argued that the degree to which individuals pursue careers in a broad or narrow range of international contexts has consequences for the development of knowledge and competencies. Relying on the notion that internationally experienced newcomers are considered a potentially valuable source of knowledge in teams, contributions to team performance are expected to be higher for newcomers with broad international backgrounds, as these newcomers are less susceptible to stereotyping and biased perceptions, possess broad and flexible knowledge and competencies that are better transferable across contexts, and may rely on hands-on experience with earlier socialization and integration occasions. These arguments thus suggest that:

H1. Newcomers' with broad international backgrounds are more likely to positively contribute to team performance.

\section{Newcomers in experientially homogeneous teams}

Past research has suggested that one reason to set up experientially diverse teams is to increase the resource pool available (e.g. Ancona \& Caldwell, 1992). Based on an information 
processing perspective of team diversity (cf. Hinsz, Tindale, \& Vollrath, 1997), it has been argued that teams may profit from a diverse experiential resource pool via learning, insight, and problem-solving effectiveness (e.g. Jackson, 1992; Van Knippenberg, De Dreu, \& Homan, 2004). Given the notion that experientially diverse composition is thus beneficial for team performance, homogeneous teams face a comparative disadvantage. With this, the information requirements in experientially homogeneous teams are characterized by the key challenge to broaden the available pool of knowledge and information. As a potential source of knowledge that is not yet represented in the team (cf. March, 1991), newcomers appear as a means to broaden the available knowledge base in experientially homogeneous teams via the infusion of new ideas, perspectives, and information (e.g. Levine \& Choi, 2004; Levine, Choi, \& Moreland, 2003).

In the first place, newcomers may thus contribute to team performance of experientially homogeneous teams by helping to overcome resource constraints. At the same time, prior research has highlighted the importance of considering predominant patterns of cooperation and communication to assess newcomers’ influence (e.g. Lee \& Allen, 1982). Experientially homogeneous teams rely on a relatively narrow but deep pool of available knowledge where each individual team member adds very similar knowledge and competencies. Team members are thus relatively aligned in terms of their experiential backgrounds, leading to significant barriers to newcomers’ likelihood to effectively integrate and contribute to team performance. Prior research suggests that experientially diverse teams may face conflict in terms of how to proceed with certain tasks or how to delegate responsibilities, whereas experientially homogeneous teams encounter less difficulty in reaching a consensus on how to cooperate (Jehn, Northcraft, \& Neale, 1999; Jehn, 1997). This implies that experientially homogeneous teams are likely to develop strong and highly accepted patterns of cooperation which new team members have to adapt to. 
Broad and flexible knowledge and competencies held by newcomers with broad international backgrounds are thereby considered to be more easily transferable and adaptable to prevailing patterns of cooperation than the relatively context-dependent knowledge and competencies held by individuals with narrow backgrounds. Further, team newcomers face the risk of being perceived by existing team members in stereotyped and biased ways based on their experiential background characteristics, hindering the effective interaction and cooperation with other team members. These disadvantages might be especially salient where existing team members are highly aligned in terms of their backgrounds, as in experientially homogeneous teams. Newcomers with broad experiential backgrounds should be less strongly identified with single experiential domains (Bunderson \& Sutcliffe, 2002), and are thus likely to be more easily socialized than their counterparts with more narrow backgrounds.

The preceding argument suggests that newcomers' external knowledge and competences are considered a valuable asset in experientially homogeneous teams. At the same time, such teams constitute an environment where the potential problems associated with newcomers might be especially salient, amplifying the expected advantages of broad over narrow international backgrounds. Accordingly, contributions to team performance are expected to be highest for newcomers’ with broad experiential backgrounds in experientially homogeneous teams. In formal terms:

H2. The positive relationship between newcomers' broad international backgrounds and contributions to team performance is more pronounced when joining experientially homogeneous teams.

\section{Newcomers in long tenured teams}

From an interest in experiential team composition, several studies have focused on the effects of team members' average tenure, a compositional dimension which is sometimes also 
referred to as team experience (Humphrey, Morgeson, \& Mannor, 2009) or shared experience (Berman, Down, \& Hill, 2002). This literature suggests that higher levels of average tenure facilitate team functioning and performance in three ways (Humphrey, Morgeson, \& Mannor, 2009): members are able to develop shared mental models (Kim, 1997), transactive memory (Austin, 2003; Wegner, 1986), and an improved understanding about the roles of other team members. Teams which have developed shared mental models possess a certain amount of commonly held knowledge which is shared by all team members and profit from superior coordination and helping behaviors (Mathieu, Heffner, Goodwin, Salas, \& Cannon-Bowers, 2000; Cannon-Bowers \& Salas, 2001).

Similarly, research on transactive memory suggests that the development of collective memory systems increases a team's awareness of which members hold specific information, knowledge, or expertise (e.g. Liang, Moreland, \& Argote, 1995; Moreland, 1999). This in turn enables teams to tap and utilize specific knowledge when needed (Bunderson, 2003b). Moreover, established and accepted role composition in teams facilitates team functioning and ultimately team performance (Humphrey, Morgeson, \& Mannor, 2009). As a sum of these mechanisms, longer-tenured teams develop towards an increasingly well-functioning unity by learning about the perspectives of other members and accumulating a stock of valuable collective knowledge (Pelled, Eisenhardt, \& Xin, 1999; Berman, Down, \& Hill, 2002).

These positive effects of shared experience, however, have been found to decrease in teams where members have acquired very high levels of shared experience (Katz, 1982). Where team members have been working together for long periods of time, teams may become increasingly inward oriented and less able to implement changes to their experiential configuration. According to Berman, Down, and Hill (2002), after an initial learning period where teams profit from developing a stock of collective knowledge, a process of knowledge ossification sets in where thought processes and interactions become routinized and taken-for- 
granted. With this, long tenured teams also become more prone to inertial behavior, rigidity, and resistance to change and new solutions (Perretti \& Negro, 2007). With this, the information requirements in long tenured teams are characterized by a need to infuse new knowledge that helps overcoming these problems (cf. Berman, Down, \& Hill, 2002).

Meanwhile, when it comes to the integration of new team members, longer tenured teams may pose substantial barriers. In order to successfully interact and cooperate with existing team members, newcomers have to adapt and adjust to predominant role structures, and integrate their external knowledge into established and well-functioning coordination processes. Where the introduction of new knowledge has a disruptive effect on team functioning, newcomers might actually cause problems with information processing and coordination, resulting in negative effects on overall team performance (Choi \& Thompson, 2005; Hinsz, Tindale, \& Vollrath, 1997). Broad and flexible knowledge and competencies introduced by newcomers having pursued broad international careers is thereby considered better adaptable and less disruptive to the well-rehearsed patterns of cooperation in longer tenured teams.

The preceding argument suggests that newcomers are considered a valuable asset in long tenured teams. Well-established and functioning patterns of cooperation may at the same time pose substantial hurdles for newcomers' to successfully contribute in long tenured teams. These conditions reinforce the advantages of newcomers' broad international backgrounds. Accordingly, contributions to team performance are expected to be highest where newcomers' with broad international backgrounds join longer tenure teams. Thus:

H3. The positive relationship between newcomers' broad international backgrounds and contributions to team performance is more pronounced when joining longer tenured teams. 


\section{METHODS}

\section{Setting and sample}

The setting to empirically test the proposed relationships is the world of professional football in the German Bundesliga. Professional sport teams are regularly confronted with challenges to integrate new team members, as changes in the player roster occur relatively frequently. As the hiring of new players is a high financial investment and associated with considerable uncertainties (De La Torre-Ruiz \& Aragon-Correa, 2012), the sport team setting allows to study newcomers in a context where their fast and successful integration is highly relevant for overall team effectiveness. Moreover, the highly dynamic environment of professional football, where mobility between clubs, leagues and countries, characterizes individual players' careers enables to study a large number of new player appointment situations. In addition, this particular setting offers advantages for the study of new team members’ international experience backgrounds: As the German Bundesliga is considered to be one of the most competitive football leagues in the world, players from various nations with highly international backgrounds are composed to play together in 18 teams per season. Importantly, the field of highest-level professional football is a setting where international experiences form a valuable and widely-spread asset. As football is considered a physical as well as cultural experience (Szymanski \& Zymbalist, 2005), a player’s knowledge about the game of football, such as style of play and the relative emphasis on the countless skills of the game, is influenced by the cultures in which the game is learned (cf. McNamara \& Peck, 2010).

Recent research in the context of professional sport has supported this notion and found that differences in players' skills exist as a function of country-specific training methods and environments (Brandes, Franck, \& Theiler, 2009; Osborne, 2006; Kahane, 
Longley, \& Simmons, 2012). With the verdict of the European Court of Justice in the case of the Belgian football player Jean-Marc Bosman in 1995, operating modes in national football leagues have changed dramatically (Frick, 2007). As a result of the major regulatory and structural changes following the Bosman ruling, professional football players have exhibited rising levels of mobility between clubs and leagues (countries). Today, Europe's most competitive football leagues are characterized by high degrees of internationality, both in terms of national origin and experiential backgrounds of players. In the 2009/10 German Bundesliga season, $55 \%$ of all players having at least one appearance on the pitch have acquired experiences other than in the home country, whereby these experiences have been acquired from a total of 58 different countries. The setting of German Bundesliga football thus allows investigating highly internationalized teams and individuals.

The analysis is based on all new player appointments in German Bundesliga football from 2005 to 2012. In order to being able to study the relationship between prior career background and subsequent contributions to team performance, the analysis did not include players in their first year as a professional footballer. Further, players having not spent the full season with their newly joined teams were excluded. With this, comparable conditions in the competitive environments of teams are created, as every team is facing opponents twice over the course of a full season. Publicly available information on individuals' careers as well as teams’ performances allowed to take advantage of a complete individual and team-level data set on key study constructs. Data collection relied on several well-established online resources, such as the official website of the German Bundesliga (bundesliga.de) and official club websites as the primary sources, as well as larger online databases providing a broad spectrum of football data (weltfussball.com, footballdatabase.eu, playerhistory.com) as complementary sources. A complete data set was compiled containing the following information: career information on 726 new players (e.g. number of different countries and corresponding length of appointments over the full career), information on the 126 seasonal 
teams which these new players joined (e.g. average market values of players, managerial tenure, squad size, average team tenure, number of new players acquired), as well as more general information on the 27 clubs fielding the season specific teams (average attendance over the study's time frame). With individual newcomers joining season specific teams that are fielded by different clubs, the design of the present study implies a hierarchical data structure containing three different levels. Both the calculation of measures and the analytical procedures accounted for this multilevel data structure.

\section{Measures}

All measures were calculated on a seasonal basis, taking account of individual games’ team compositions (line-up reports) and outcomes (game results). Career backgrounds of new players as well as overall team measures include information up until the start of a specific season.

The dependent variable performance contribution as an individual level indicator of newcomers' involvement in successful team production draws upon a documentation of players’ appearances in individual games (34 Bundesliga game days per team correspond to a maximum of 34 appearances). In a first step, the number of points the team has acquired in matches where a new player was fielded were counted. In line with rules and standards of the German Bundesliga, this precedure accounted 3 points in case of a win, 1 point for a draw, and 0 points for a loss. The total number of points acquired when being on the pitch served as an initial estimate for new team members' contributions. In order to account for new players' eligibility to be fielded by the responsible team coach, the sum of points acquired was divided by the number of games where a new player was in principle eligible to play (i.e. the player was not injured or blocked to play due to any official restrictions or regulatory issues). Eligibility was estimated by counting the number of appearances on the official match report, either as a starting line-up player or a bench player. Performance contribution was calculated 
as the natural logarithm of the resulting ratio. This measure of performance contribution as an individual-level variable captures the extent to which new team members have significantly added to successful team performance in a newly joined team.

Three main independent variables are employed: At the individual level, broad international background serves as an indicator of the relative breadth in newcomers' experience backgrounds. Relying on Blau's (1977) diversity index, this measure was calculated according to the following formula: $1-\sum p_{i}^{\wedge} 2$, where $p$ is the percentage of total experience acquired in country $i$. This measure captures the extent to which a new player has acquired experience in a broad or narrow set of countries prior to joining a new team and has been used as an indicator of individuals' career diversity both in a business context (Bunderson \& Sutcliffe, 2002, Dahlin, Weingart, \& Hinds, 2005) and in a sports context (Ruigrok, Greve, \& Engeler, 2011).

At the seasonal team level, experiential homogeneity serves as an indicator of the relative breadth in a teams' overall pool of available knowledge and experiences. According to this paper's main interest, the measure relies on international experiences as the focal experiential attribute and was calculated according to the following procedure. First, the total number of years of experience in every country at team level was calculated by summing up all individual player background inputs (e.g. 2 years of experience in England by player A added to 5 years of experience in England held by player B). Second, Blau's (1977) diversity index was adapted to determine the homogeneity in international experiences according to the following formula: $\sum p_{i}^{\wedge}$, where $p$ is the percentage of experience the team holds from country $i$. This measure captures the extent to which a team carries a relatively homogeneous pool of knowledge and information with respect to international experience. As a second indicator of experiential team composition at the seasonal team level average team tenure was calculated as all team members' average number of games played for the current club in 
previous consecutive seasons. This measure captures the extent to which a team is composed of long tenured or relatively newly appointed members.

Control variables at the individual level, the seasonal team level, and the club level were included in the analysis: As the literature on organizational socialization suggests, the integration of newcomers, i.e. individuals which have not been members of a certain organization in the past, poses challenges to both the newcomers and the existing team, especially when newcomers are different to existing team members (e.g. Jackson, Stone, \& Alvarez, 1993). According to this study's main focus on experiential team composition, the individual level control variable dominant country dissimilarity is employed to capture the degree to which newcomers' experience backgrounds are substantially different from backgrounds of other team members. In a first step, and in line with earlier approaches to operationalize individuals' experience backgrounds (e.g. Bunderson \& Sutcliffe, 2002), the dominating country-specific experiential influence in each player's career background was determined by identifying the country where a player had acquired the most experience in. If two countries exhibited the same amount of experience, the country where a player had acquired experience more recently was chosen as the dominating influence.

To calculate the degree of dissimilarity between newcomers' and existing team members' dominant country, the squared proportion of existing team members sharing the same dominant country with a newcomer was subtracted from 1 . This procedure accords established approaches to operationalize dissimilarity in categorical variables (Boone, van Olffen, van Witteloostijn, \& De Brabander, 2004). As a further control at individual player level, a dummy variable distinguishing between offensive and defensive players is included, whereby midfielders and strikers were assigned to the offensive category and goalkeepers and defenders assigned to the defensive category. At seasonal team level, team market value is included as a control variable. Prior research on the performance determinants of professional sport teams has suggested a strong impact of players' market values, as these constitute an 
efficient measure of players’ skill level, talent, or quality (e.g. Bridgewater, Kahn, \& Goodall, 2011). Following the procedure suggested by Depken (1999), the analysis thus includes the logarithm of players' average market values as estimated by Kicker soccer magazine and adjusted to 2009 Euros.

Further, managerial tenure accounts for the influence of a team's manager or coach. Prior research has demonstrated an influential role of the team manager on team functioning and performance. Longer tenured coaches have the potential to implement significant changes that influence performance through individual and group learning (Rowe, Cannella, Rankin, \& Gorman, 2005), or the implementation of a successful strategy (Wright, Smart, \& McMahan, 1995). Managerial tenure was calculated as the number of consecutive years of experience a team's coach had acquired with the current team in prior seasons. If, as a result of managerial succession, more than one coach had been active during a given season, an average measure was calculated by weighting each coach's influence by the number of months in charge. As joining larger teams may diminish the chances of a new player to appear on the pitch and then help the team to win points, team size controls for the overall size of the squad, and was determined as the number of players with actual playing time over the course of the full season.

As a further control at seasonal team level, number of new players accounts for the total number of new players joining a team, as the challenges associated with integrating in a new team might be dependent on whether newcomers join a team as a single new member of as a part of larger group. At club level the analysis controls for the average attendance, i.e. the average number of spectators at home games over the 7 year period from 2005 to 2012 in 1st and 2nd Bundesliga, as a means to proxy the overall reputation or standing of a club over time. Finally, seasonal year dummies are included in the analysis to account for unobservable time effects. 


\section{Analysis}

This study's research design resulted in a nested hierarchical data structure with three distinct levels (individual level, seasonal team level, and club level). Consequently, a threelevel hierarchical modeling (HLM) technique was employed to analyze the data (Raudenbush \& Bryk, 2002). Hierarchical linear modeling addresses the concern that dependence in the data arises from the nested data structure as it "provides the correct parameter estimates and significance tests for multilevel and non-independent data” (Chen, Kirkman, Knafer, Allen, \& Rosen, 2007, p. 337). Thus, at the first level of analysis, individual newcomer differences are examined. At the second level, potential differences between teams where new members are appointed are considered. And at the third level, differences between clubs are observed.

In hierarchical multilevel modeling special attention should be given to centering decisions. Lower level variables can be centered at the grand mean or at the group mean, i.e. centering within clusters (Enders \& Tofighi, 2007). Centering at the group mean removes all between-group variation, and thus group-mean centered variables are uncorrelated with higher-level variables. Therefore, consistent with HLM conventions, group-mean centering is considered as the appropriate procedure for all variables of special interest in order to receive pure estimates of the respective level variance. Specifically, all individual level variables as well as seasonal team level variables of special interest (experiential homogeneity and average team tenure) were group-mean centered and all other variables were grand-mean centered. Hypotheses were tested with a series of hierarchical linear models.

\section{RESULTS}

Table 1 presents correlations as well as means and standard deviations for the variables of interest. As shown in the table, correlations do not exceed a maximum level of 0.572 (between team market value and average attendance). An ordinary least squares 
replication of the models did reveal variation inflation factors all below values of 5 . According to generally applied rules to detect multicollinearity by using VIFs (O’Brien, 2007), these values indicate that multicollinearity is not an issue in the present analysis.

$* * * * * * * * * * * * * * * * *$

Insert Table 1 about here

Table 2 presents results of the HLM null model (empty model) in which no independent or control variables are included. The depicted decomposition allows assessing how the variance at three levels affects the variance among observations of the dependent variable at individual level (Raudenbush \& Bryk, 2002). As these numbers indicate, the individual new player level explains a vast majority of more than $70 \%$ of the variance in newcomers' contributions to team performance. Higher levels explain the remaining variance, with $17 \%$ at seasonal team level and $10 \%$ at club level. These results are statistically significant $(\mathrm{p}<0.001)$ and indicate that it is reasonable to include predictors at higher levels as explanatory factors of the individual level dependent variable into the models. Table 3 presents a series of hierarchical linear models to test the main effect hypothesis as well as moderating hypotheses.

Insert Tables 2 and 3 about here

Model 1 includes all higher-level variables. Results indicate that average attendance ( $\mathrm{p}<$ $0.01)$, team market value $(\mathrm{p}<0.01)$, managerial tenure $(\mathrm{p}<0.05)$, and number of new players 
$(\mathrm{p}<0.05)$ all positively and significantly influence newcomers' contributions to team performance. Team size $(\mathrm{p}<0.001)$ and average team tenure $(\mathrm{p}<0.1)$ report a negative and significant relationship to the outcome variable. These effects are stable across extensions of the baseline model and suggest that higher-level explanatory factors account significantly for variance in the individual level outcome variable. Generally, relationships are in expected directions. The results on average attendance as an indicator of a clubs' standing or reputation indicate that newcomers profit from a well-established and professional environment. Newcomers' also profit from high quality team mates surrounding them, as indicated by the findings on team market value. Teams consisting of high quality players might accordingly be better able to integrate new players. Further, longer tenured coaches positively influence performance contributions of new players, a finding that could indicate how over the time of their employment spell, coaches successfully match the characteristics of new players with the preferred strategy and existing human capital base of their teams (Rowe, Cannella, Rankin, \& Gorman, 2005; Wright, Smart, \& McMahan, 1995).

Supplementary analysis did not indicate a significant interaction between managerial tenure and newcomers' broad international backgrounds. The positive relationship between the number of new players and newcomers' performance contributions could indicate how new players, when joining a team as a part of a larger cohort, face less resistance and marginalization from existing team members in the socialization process. The negative and significant influence of team size might be due to the fact that appearances on the pitch, and thereby the possibility to contribute to team performance, is limited to a maximum of 14 players per game day. Larger teams might occasionally take advantage of the possibility to leave some of their players on the bench ("rotation strategy”). Further, a negative coefficient of the average team tenure variable indicates that long tenured teams pose substantial barriers that newcomers need to overcome in their ambitions to successfully contribute to team performance. 
Introducing individual player variables in model 2 substantially increases model fit, as indicated by the lower deviance scores. Control variables at individual level indicate that dominant country dissimilarity negatively influences newcomers' performance contributions ( $p<0.05)$, and offensive newcomers significantly contribute more $(p<0.001)$. Meanwhile, Model 2 reveals a positive and significant relationship between newcomers' broad international backgrounds and contributions to team performance $(\mathrm{p}<0.05)$, thereby offering statistical support for hypothesis 1 .

Supplementary analysis was conducted to examine the significantly positive association of offensive players with the outcome variable. Including dummy variables for specific tactical playing positions (i.e. goalkeepers, defenders, midfielders, and strikers) revealed that this effect is due to the significantly lower performance contributions of new goalkeepers in comparison to field players. As goalkeepers are only very rarely substituted during games, new joining goalkeepers could likely face the situation to be in the position of a team's second goalkeeper, with regular bench nominations but only very few appearances on the pitch. As a result, such players have little possibilities to actually contribute to team performance on the pitch, leading to low scores in this study's dependent variable. As a robustness test to this study's findings, the analysis was therefore repeated excluding all goalkeepers from the newcomer sample. Importantly, findings were confirmed by this robustness test, as identical directions of all relationships were found with significance levels well in the range of statistical significance. Reported findings refer to the full sample including the goalkeepers in order to provide a more complete picture of the analysis.

Moderating effects of experiential homogeneity and average team tenure on newcomers' broad international experience backgrounds to explain performance contributions were tested in models 3 and 4. Hypotheses 2 and 3, which predicted positive interaction effects, are supported by the statistical findings with $\mathrm{p}<0.1$ for hypothesis 2 , and $\mathrm{p}<0.01$ for 
hypothesis 3. Figures 1 and 2 graphically illustrate these moderation effects. Higher and lower levels of the moderating variables are depicted at plus/minus 1 standard deviation.

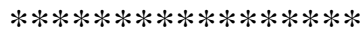

Insert Figures 1 and 2 about here

Generally, breadth in international backgrounds appears as an influential determinant of newcomers’ performance contributions especially in experientially homogeneous and long tenured teams. In experientially diverse and shorter tenured teams, breadth in international backgrounds is less influential in explaining differential performance contributions, as indicated by much flatter slopes of the respective interaction graphs. Consistent with the predictions in hypotheses 2 and 3, these graphs further illustrate that performance contributions are highest when newcomers with broad international backgrounds join experientially homogeneous and long tenured teams. At the same time, newcomers with relatively narrow backgrounds apparently are able to contribute more when joining diverse and shorter tenured teams.

\section{DISCUSSION}

Prior research has often framed newcomers as a source of fresh external knowledge and competencies to benefit teams. Focusing on newcomers' knowledge and competencies acquired during international careers, this study finds that the relative breadth in new team members' international experience backgrounds has decisive influence on the degree to which such expected benefits translate into subsequent performance contributions. It appears that broad international experience backgrounds enable newcomers to better contribute to team 
performance opposed to relatively narrow backgrounds. Further, these effects are dependent on the specific experiential composition of the newly joined team, suggesting that internationally experienced newcomers contribute differently to different types of teams. Together, these insights shed new light on the determining factors of newcomer performances in team settings. First and foremost, implications thus arise for researchers and practitioners interested in experiential team composition.

With teams facing the challenge of increasingly dynamic composition where members frequently move on and off teams (Mathieu, Maynard, Rapp, \& Gilson, 2009; Tannenbaum, Mathieu, Salas, \& Cohen, 2012), it is important to better understand which newcomers are likely to contribute the most under which conditions. Focusing on the determinants of newcomer performance in team situations, prior research has recognized the role of newcomers' experiences, but predominantly focused on the degree to which experiences in related industry or occupational work contexts facilitate the socialization in and contribution to new teams (e.g. Dokko, Wilk, \& Rothbard, 2009; Chen \& Klimoski, 2003; Adkins, 1995). The present study confirms this prior research in that experiential characteristics appear as an important determinant of later contributions in new teams, and exceeds existing studies by examining international experience as a new dimension in the conceptualization of newcomers' backgrounds. Understanding the effects on international experiences is crucial, as individuals' career paths may well span several international environments while at the same time remaining within the boundaries of specific industries or occupations. Future research designs should thus consider international experiences in conceptualizations of individuals' backgrounds. From the perspective of experiential team composition, breadth in individuals' experience backgrounds may serve as a criterion to assess the expected performance contributions of potential new team members and should be considered in team staffing decisions. 
Offering a more precise picture, the conducted analysis of moderation effects reveals that individuals with broad or narrow backgrounds contribute to different extents to overall team performance when joining different types of teams. As depicted in Figures 1 and 2, when joining experientially homogeneous or long tenured teams, newcomers with broad backgrounds contribute significantly more to team performance than newcomers with more narrow backgrounds. At the same time, such differential effects are less recognizable when joining experientially diverse or shorter tenured teams. In more abstract terms, these insights thus suggest that experientially homogeneous and longer tenured teams are characterized by information requirements and cooperation patterns that are sensitive to the degree to which newcomers' broad or narrow knowledge and competencies constitute valuable and beneficial inputs. Conditions in experientially diverse and shorter tenured teams appear to be different since less sensitive to this distinction between newcomers' broad or narrow backgrounds. Thus, managers responsible for team composition should take careful decisions in appointing individuals with broad backgrounds over such with narrow backgrounds the more a team is characterized as experientially homogeneous and long tenured.

This study's conceptualization of newcomers' experience backgrounds along a spectrum from narrow to broad backgrounds resembles other researchers' approaches to distinguish between specialists (with narrow backgrounds) and generalists (with broad backgrounds) (e.g. Bunderson \& Sutcliffe, 2002). Prior research has examined groups’ compositions of specialist and generalist members, and argued that generalists are more likely to share similar knowledge with other team members, thereby facilitating the exchange of information (e.g. Rulke \& Galaskiewicz, 2000; Liang, 1994; De La Torre-Ruiz, AragonCorrea, \& Ferron-Vilchez, 2011). Importantly, the present study adds to this prior research by applying this distinction to an investigation of newcomers' performances in teams, thereby offering insights into the contributions of individual specialists and generalists in team settings. Broader backgrounds, i.e. generalist backgrounds, were found to enable newcomers 
to better contribute to team performance, with these effects being more pronounced when joining experientially homogeneous and longer tenured teams.

Further implications follow from some of the analysis’ results on the control variables. These reveal a significant negative effect of dominant country dissimilarity on newcomers' contributions to team performance, indicating that new team members' experience backgrounds which are dissimilar to those of other team members with respect to the most dominating influence hinder the transferability and applicability of acquired knowledge and competencies. In addition, this study's main finding highlights that breadth in international experience backgrounds facilitates contributions in new team settings. Together, the two dimensions of dominant country dissimilarity and breadth in backgrounds may serve to delineate a stylized picture of international careers and derive implications for the expected transferability and adaptability of acquired knowledge in new team settings (cf. Eby, Butts, \& Lockwood, 2003). The more an individual has acquired experiences in a multitude of international environments and thereby kept a dominating influence that is similar to the one in other team members' backgrounds, the better that individual will be able to contribute to the performance of a newly joined team. In many cases, the home country context will be the dominating influence in most team members' experience backgrounds. This implies that a promising career path leading to the development of highly transferable and readily applicable knowledge and competencies consists of several shorter termed international assignments as an extension of a remaining dominating home country influence. Moreover, results on the managerial tenure control variable reveal that longer tenured coaches have a positive influence on newcomers' contributions to team performance. Where teams face highly dynamic conditions of frequent change in membership, continuity in leadership thus appears as a promising strategy to maximize the performance contributions of new team members.

Several limitations to this study are identified, which also serve to delineate future research directions. A possible concern with this study is its empirical focus on the setting of 
professional football. Professional football teams might be considered comparable to other types of teams only to a limited extent, thereby hindering a meaningful interpretation and application of findings across different teams and contexts. Recently, Hollenbeck, Beersma, and Schouten (2012) have suggested the three dimensions of skill differentiation, authority differentiation, and temporal stability that may serve as critical dimensions to compare and contrast different teams and assess the degree to which findings can be applied across teams and contexts. Levels of skill differentiation, authority differentiation, and temporal stability therefore represent boundary conditions to the present study, suggesting that findings are most meaningfully applied to settings where teams share essential characteristics with the professional football teams examined herein.

Skill differentiation refers to the degree to which individual team members have specific and unique skill sets that limit their interchangeability (Hollenbeck, Beersma, \& Schouten, 2012). Within the context of professional football, individual players have developed the skills necessary to fulfill specialized roles in a highly competitive team, such as goalkeeper, defender, or striker. At the same time, due to the high importance of certain football core skills such as running, passing, and shooting, individual members are able to at least temporarily take over roles not lying in their primary field of specialization. With this, professional football teams share elements of both high and low degrees of skill differentiation. Importantly, these characteristics of football teams' skill differentiation are also likely to influence the integration of new players in the team production process, due to the high relevance of certain core skills and football teams' general reliance on wellestablished roles (i.e. tactical playing positions) that facilitate the cooperation between newcomers and other team members. It has been argued that common routines and conventions facilitating the integration and coordination of previously unacquainted individuals also exist in other settings, such as the cultural industries (Perretti \& Negro, 2007; Jones, 1996). Still, future research should examine how different levels of skill differentiation 
influence the relationships between newcomers' prior experience backgrounds and contributions to team performance proposed in this study. Authority differentiation refers to the degree to which clearly identifiable leadership roles influence team functioning (Hollenbeck, Beersma, \& Schouten, 2012).

In the context of professional sport teams, managers have been ascribed central roles in that they influence and decide on the staffing of teams, the development of individual players, and the selection and implementation of an appropriate strategy (e.g. Carmichael, McHale, \& Thomas, 2011; Audas, Dobson, \& Goddard, 2002; Rowe, Cannella, Rankin, \& Gorman, 2005). The present study suggests that coaches also facilitate contributions of new team members, in that longer tenured coaches have been found to be positively associated with newcomers' contributions to team performance. Future research could thus examine the specific role of managers in facilitating newcomers' contributions in more detail. With a focus on the dimension of temporal stability, teams that are stable and have a future and history together are distinguished from teams that may work together only for the purpose of a special short-termed occasion (Hollenbeck, Beersma, \& Schouten, 2012).

The professional football teams examined in the present study can be considered relatively long termed teams, which are composed to perform over the course of a full season. The temporal stability of the teams examined, and the chosen time frame of a full season pose boundary conditions to the findings reported in this study, as prior research has demonstrated how newcomers' performances may improve over the stages of a socialization process (e.g. De La Torre-Ruiz \& Aragon-Correa, 2012; Chen, 2005). This implies that examining different time frames could have yielded different relationships between newcomers' backgrounds and contributions to team performance. Future research could thus assess whether newcomers' contributions as a function of experiential backgrounds change over time and how newcomers contribute to more short termed or even longer termed teams. 
Further, this study has focused on a single dimension of individuals' experience backgrounds, i.e. international experiences. At the same time, experience has been described as a complex and multidimensional construct (Tesluk \& Jacobs, 1998; Quinones, Ford, \& Teachout, 1995), and prior research has offered a great deal of work suggesting how dimensions such as functional (e.g. Bunderson \& Sutcliffe, 2002; Bunderson, 2003b) or educational experiences (e.g. Dahlin \& Weingart, 2005) affect individuals' intrateam involvement and contributions to team processes. These insights suggest that a promising avenue for future research is to examine the combined effects of multiple experiential dimensions on newcomers' performance contributions. The special contribution of the present study thereby lies in a focused analysis of the effects of international experiences that should inspire future research to further explore this increasingly important dimension of contemporary career backgrounds. 


\section{REFERENCES}

Adkins, C.L. 1995. Previous work experience and organizational socialization: A longitudinal examination. The Academy of Management Journal, 38(3) : 839-862.

Almeida, P., Dokko, G., \& Rosenkopf, L. 2003. Startup size and the mechanisms of external learning: Increasing opportunity and decreasing ability? Research Policy, 32(2): 301-315.

Ancona, D.G., \& Caldwell, D.F. 1992. Demography and design: Predictors of new product team performance. Organization Science, 3(3): 321-341.

Arthur, M.B., \& Rousseau, D.M. 1996. The boundaryless career as a new employment principle. M.B. Arthur, \& D.M. Rousseau, eds. The Boundaryless Career. Oxford University Press, New York: 3-20.

Audas, R., Dobson, S., \& Goddard, J. 2002. The impact of managerial change on team performance in professional sports. Journal of Economics and Business, 54: 633650.

Austin, J.R. 2003. Transactive memory in organizational groups: The effects of content, consensus, specialization, and accuracy on group performance. Journal of Applied Psychology, 88: 866-878.

Bauer, T.N., Bodner, T., Erdogan, B., Truxillo, D.M., \& Tucker, J.S. 2007. Newcomer adjustment during organizational socialization: A meta-analytic review of antecedents, outcomes, and methods. Journal of Applied Psychology, 92(3): 707721.

Berman, S.L., Down, J., \& Hill, C.W.L. 2002. Tacit knowledge as a source of competitive advantage in the national basketball association. Academy of Management Journal, 45(1): 13-31.

Bhagat, R.S., Kedia, B.L., Harveston, P.D., \& Trianidis, H.C. 2002. Cultural variations in the cross-border transfer of organizational knowledge: An integrative framework. Academy of Management Review, 27(2): 204-221.

Blau, P. 1977. Inequality and heterogeneity. New York: Free Press.

Bonache, J., Brewster, C., \& Suutari, V. 2001. Expatriation: A developing research agenda. Thunderbird International Business Review, 43(1): 3-20.

Boone, C., van Olffen, W., van Witteloostijn, A., \& De Brabander, B. 2004. The genesis of top management team diversity: Selective turnover among top management teams in Dutch newspaper publishing. Academy of Management Journal, 47: 633-656. 
Brandes, L., Franck, E., \& Theiler, P. 2009. The effect from national diversity on team production - empirical evidence form the sports industry. Schmalenbach Business Review, 61: 225-246.

Bridgewater, S., Kahn, L.M., \& Goodall, A.H. 2011. Substitution and complimentarity between managers and subordinates: Evidence from British soccer. Labour Economics, 18: 275-286.

Bunderson, J.S. 2003a. Team member functional background and involvement in management teams: Direct effects and the moderating role of power centralization. Academy of Management Journal, 46(4): 458-474.

Bunderson, J.S. 2003b. Recognizing and utilizing expertise in work groups: A status characteristics perspective. Administrative Science Quarterly, 48(4): 557-591.

Bunderson, J.S., \& Sutcliffe, K.M. 2002. Comparing alternative conceptualizations of functional diversity in management teams: Process and performance effects. Academy of Management Journal, 45(5): 875-893.

Cannon-Bowers, J.A., \& Salas, E. 2001. Reflections on shared cognition. Journal of Organizational Behavior, 22: 195-202.

Cappellen, T., \& Janssens, M. 2005. Career paths of global managers: Towards future research. Journal of World Business, 40: 348-360.

Carmichael, F., McHale, I., \& Thomas, D. 2011. Maintaining market position: Team performance, revenue and wage expenditure in the English premier league. Bulletin of Economic Research, 63(4): 464-497.

Carpenter, M.A., Sanders, W., \& Gregersen, H.B. 2001. Bundling human capital with organizational context: the impact of international assignment experience on multinational firm performance and CEO pay. Academy of Management Journal, 44(3): 493-511.

Carpenter, M.A., Sanders, W.G., \& Gregersen, H.B. 2000. International assignment experience at the top can make a bottom-line difference. Human Resource Management, 39: 277-285.

Castanias, R.P., \& Helfat, C.E. 2001. The managerial rents model. Journal of Management, 27: 661-678.

Chen, G. 2005. Newcomer adaptations in teams: Multilevel antecedents and outcomes. Academy of Management Journal, 48(1): 101-116. 
Chen, G., Kirkman, B.L., Kanfer, R., Allen, D., \& Rosen, B. 2007. A multilevel study of leadership, empowerment, and performance in teams. Journal of Applied Psychology, 92: 331-346.

Chen, G., \& Klimoski, R.J. 2003. The impact of expectations on newcomer performance in teams as mediated by work characteristics, social exchanges, and empowerment. Academy of Management Journal, 46(5): 591-607.

Choi, H.S., \& Thompson, L. 2005. Old wine in a new bottle: Impact of membership change on group creativity. Organizational Behavior and Human Decision Processes, 98: 121-132.

Dahlin, K.B., Weingart, L.R., \& Hinds, P.J. 2005. Team diversity and information use. The Academy of Management Journal, 48(6): 1107-1123.

De La Torre-Ruiz, J.M., \& Aragon-Correa, J.A. 2012. Performance of newcomers in highly interdependent teams: The case of basketball teams. European Sport Management Quarterly, 12(3): 205-226.

De La Torre-Ruiz, J.M., Aragon-Correa, J.A., \& Ferron-Vilchez, V. 2011. Job-related skill heterogeneity and action team performance. Management Decision, 49(7) : 10611079.

Dickmann, M., \& Doherty, N. 2008. Exploring the career capital impact of international assignments within distinct organizational contexts. British Journal of Management, 19: 145-161.

Dickmann, M., \& Harris, H. 2005. Developing career capital for global careers: The role of international assignments. Journal of World Business, 40: 399-408.

Depken, C.A. 1999. Free-agency and the competitiveness of major league baseball. Review of Industrial Organizaion, 14: 205-217.

Dokko, G., Wilk, S.L., \& Rothbard, N.P. 2009. Unpacking prior experience: How career history affects job performance. Organization Science, 20(1): 51-68.

Eby, L.T., Butts, M., \& Lockwood, A. 2003. Predictors of success in the era of the boundaryless career. Journal of Organizational Behavior, 24: 689-708.

Enders, C.K., \& Tofighi, D. 2007. Centering predictor variables in cross-sectional multilevel models: A new look at an old issue. Psychological Methods, 12: 121-138.

Frick, B. 2007. The football players' labor market: Empirical evidence from the major European leagues. Scottish Journal of Political Economy, 54(3): 422-446.

Gregersen, H.B., Morrison, A.J., \& Black, J.S. 1998. Developing leaders for the global frontier. Sloan Management Review, 21-32. 
Hall, D.T. 1996. Protean careers of the 21st century. Academy of Management Executive, 10: 8-16.

Hinsz, V.B., Tindale, R.S., \& Vollrath, D.A. 1997. The emerging conceptualization of groups as information processors. Psychological Bulletin, 121(1): 43-64.

Hollenbeck, J.R., Beersma, B., \& Schouten, M.E. 2012. Beyond team types and taxonomies: A dimensional scaling conceptualization for team description. Academy of Management Review, 37(1): 82-106.

Humphrey, S.E., Morgeson, F.P., \& Mannor, M.J. 2009. Developing a theory of the strategic core of teams: A role composition model of team performance. Journal of Applied Psychology, 94(1): 48-61.

Jackson, S.E. 1992. Team composition in organizational settings: Issues in managing an increasingly diverse work force. S. Worchel, W. Wood, J. Simpson, eds. Group Process and Productivity. Sage Publications, Newbury Park, CA: 138-173.

Jackson, S.E., Stone, V.K., \& Alvarez, E.B. 1993. Socialization amidst diversity: The impact of demographics on work team oldtimers and newcomers. L.L. Cumings, \& B.M. Staw, eds. Research in Organizational Behavior, vol. 15, JAI Press, Greenwich, CT: 45-109.

Jehn, K.A. 1997. A qualitative analysis of conflict types and dimensions in organizational groups. Administrative Science Quarterly, 42: 530-557.

Jehn, K.A., Northcraft, G.B., \& Neale, M.A. 1999. Why differences make a difference: A field study of diversity, conflict, and performance in workgroups. Administrative Science Quarterly, 44: 741-763.

Jokinen, T. 2010. Development of career capital through international assignments and its transferability to new contexts. Thunderbird International Business Review, 52(4): 325-336.

Jones, C. 1996. Careers in project networks: The case of the film industry. In M.B. Arthur, \& D.M. Rousseau (eds.), The Boundaryless Career (pp. 58-75). New York: Oxford University Press.

Kahane, L., Longley, N., \& Simmons, R. 2012. The effects of coworker heterogeneity on firm-level output: Assessing the impacts of cultural and language diversity in the national hockey league. Review and Economics and Statistics, forthcoming.

Katz, R. 1982. The effects of group longevity on project communication and performance. Administrateive Science Quarterly, 27: 81-104. 
Kim, P.H. 1997. When what you know can hurt you: A study of experiential effects on group discussion and performance. Organizational Behavior and Human Decision Processes, 69: 165-177.

Kor, Y.Y. 2003. Experience-based top management team competence and sustained growth. Organization Science, 14(6): 707-719.

Lee, D.M.S., \& Allen, T.J. 1982. Integrating new technical staff: Implementations for acquiring new technology. Management Science, 28(12): 1405-1420.

Levine, J.M., \& Choi, H.S. 2004. Impact of personnel turnover on team performance and cognition. In E. Salas \& S.M. Fiore (eds.), Team Cognition: Process and Performance at the inter/intra individual level (p. 163-176). Washington, DC: American Psychological Association.

Levine, J.M., Choi, H.S., \& Moreland, R.L. 2003. Newcomer innovation in work teams. In P. Paulus \& B. Nijstad (eds.), Group Creativity: Innovation Through Collaboration (p. 202-224), New York: Oxford University Press.

Liang, D.W. 1994. The effects of top management team formation on firm performance and organizational effectiveness. Unpublished Doctoral Dissertation, Carnegie Mellon University, Pittsburg, PA.

Liang, D.W., Moreland, R.L., \& Argote, L. 1995. Group versus individual training and group performance: The mediating role of transactive memory. Personality and Social Psychology Bulletin, 21: 384-393.

March, J.G. 1991. Exploration and exploitation in organizational learning. Organization Science, 2(1): 71-87.

Mathieu, J., Maynard, M.T., Rapp, T., \& Gilson, L. 2008. Team effectiveness 1997-2007: A review of recent advancements and a glimpse into the future. Journal of Management, 34(3): 410-476.

Mathieu, J.E., Heffner, T.S., Goodwin, G.F., Salas, E., \& Cannon-Bowers, J.A. 2000. The influence of shared mental models on team process and performance. Journal of Applied Psychology, 85: 273-283.

McNamara, P. \& Peck, S.I. 2010. Resource heterogeneity and managerial experience: Sources of temporary and sustained competitive advantage. Working paper, University College Dublin, Dublin.

Moreland, R.L. 1999. Transactive memory: Learning who knows what in work groups and organizations. In L. Thompson, J. Levine, \& D. Messik (eds.), Shared Cognition in Organizations: The Management of Knowledge (p. 3-31). Mahwah, NJ: Erlbaum. 
Nahavandi, A., \& Aranda, E. (1994). Restructuring teams for the re-engineered organization. Academy of Management Executive, 8(4): 58-68.

O’Brien, R.M. 2007. A caution regarding rules of thumb for variance inflation factors. Quality and Quantity, 41: 673-690.

Osborne, E. 2006. Baseball's international division of labor. Journal of Sports Economics, 7(2): 150-167.

Ostroff, C., \& Kozlowski, S.W.J. 1992. Organizational socialization as a learning process: The role of information acquisition. Personnel Psychology, 45: 849-874.

Pelled, L.H., Eisenhardt, K.M., \& Xin, K.R. 1999. Exploring the black box: An analysis of work group diversity, conflict, and performance. Administrative Science Quarterly, 44(1): 1-28.

Perretti, F., \& Negro, G. 2007. Mixing genres and matching people: A study in innovation and team composition in Hollywood. Journal of Organizational Behavior, 28: 563-586.

Quinones, M.A., Ford, J.K., \& Teachout, M.S. 1995. The relationship between work experience and job performance: A conceptual and meta-analytic review. Personnel Psychology, 48(4): 887-910.

Rao, H., \& Drazin, R. 2002. Overcoming resource constraints on product innovation by recruiting talent from rivals: A study of the mutual fund industry. The Academy of Management Journal, 45(3): 491-507.

Raudenbush, S.W., \& Bryk, A.S. 2002. Hierarchical linear models: Applications and data analysis methods. 2nd edition. Sage, Newbury Park, CA.

Rowe, W.G., Cannella, A.A., Rankin, D., \& Gorman, D. 2005. Leader succession and organizational performance: Integrating the common-sense, ritual scapegoating, and vicious-circle succession theories. The Leadership Quarterly, 16: 197-219.

Ruigrok, W., Greve, P., \& Engeler, M. 2011. International experiential diversity and performance at project organizations. The case of national football teams. Sport, Business and Management: An International Journal, 1(3): 267-283.

Rulke, D.L., \& Galaskiewicz, J. 2000. Distribution of knowledge, group network structure, and group performance. Management Science, 46(5): 612-625.

Rynes, S.L., Orlitzky, M.O., \& Bretz, R.D. 1997. Experienced hiring versus college recruiting: Practices and emerging trends. Personnel Psychology, 50(2): 309-339.

Staw, B.M. 1980. The consequence of turnover. Journal of Occupational Behavior, 1: 253273. 
Sullivan, S.E., \& Baruch, Y. 2009. Advances in career theory and research: A critical review and agenda for future exploration. Journal of Managemen, 35(6): 1542-1571.

Suutari, V., \& Mäkelä, K. 2007. The career capital of managers with global careers. Journal of Managerial Psychology, 22(7): 628-648.

Suutari, V. 2003. Global managers: career orientation, career tracks, life-style implications, and career commitment. Journal of Managerial Psychology, 18(3): 185-207.

Szymanski, S., \& Zimbalist, A. 2005. National pastime: How Americans play baseball \& the rest of the world plays soccer. Washington, Brookings Institution Press.

Tajfel, H. 1981. Human Groups and Social Categories: Studies In Social Psychology. Cambridge, England: Cambridge University Press.

Tannenbaum, S.I., Mathieu, J.E., Salas, E., \& Cohen, D. 2012. Teams are changing : Are research and practice evolving fast enough? Industrial and Organizational Psychology, 5: 2-24.

Tesluk, P.E., \& Jacobs, R.R. 1998. Toward an integrated model of work experience. Personnel Psychology, 51(2) : 321-355.

Turner, J.C. 1982. Towards a cognitive redefinition of the social group. In H. Tajfel (ed.), Social Identity and Intergroup Relations (p. 15-40). Cambridge, England: Cambridge University Press.

Van Knippenberg, D., DeDreu, C.K.W., \& Homan, A.C. 2004. Work group diversity and group performance: An integrative model and research agenda. Journal of Applied Psychology, 89(6): 1008-1022.

Van Maanen, J., \& Schein, R.H. 1979. Toward a theory of organizational socialization. B.M. Staw, ed. Research in Organizational Behavior, vol. 1, JAI Press, Greenwich, CT: 209-264.

Vermond, K. 2001. Expatriates come home. CMA Management, 75(7): 30-33.

Wegner, D.M. 1986. Transactive memory: A contemporary analysis of the group mind. B. Mullen, \& G.R. Goethals, eds. Theories of Group Behavior, Springer-Verlag, New York: 185-205.

Wright, P.M., Smart, D.L., \& McMahan, G.C. 1995. Matches between human resources and strategy among NCAA basketball teams. The Academy of Management Journal, 38(4):1052-1074 
TABLE 1

Descriptives and Correlations of Core Variables (uncentered)

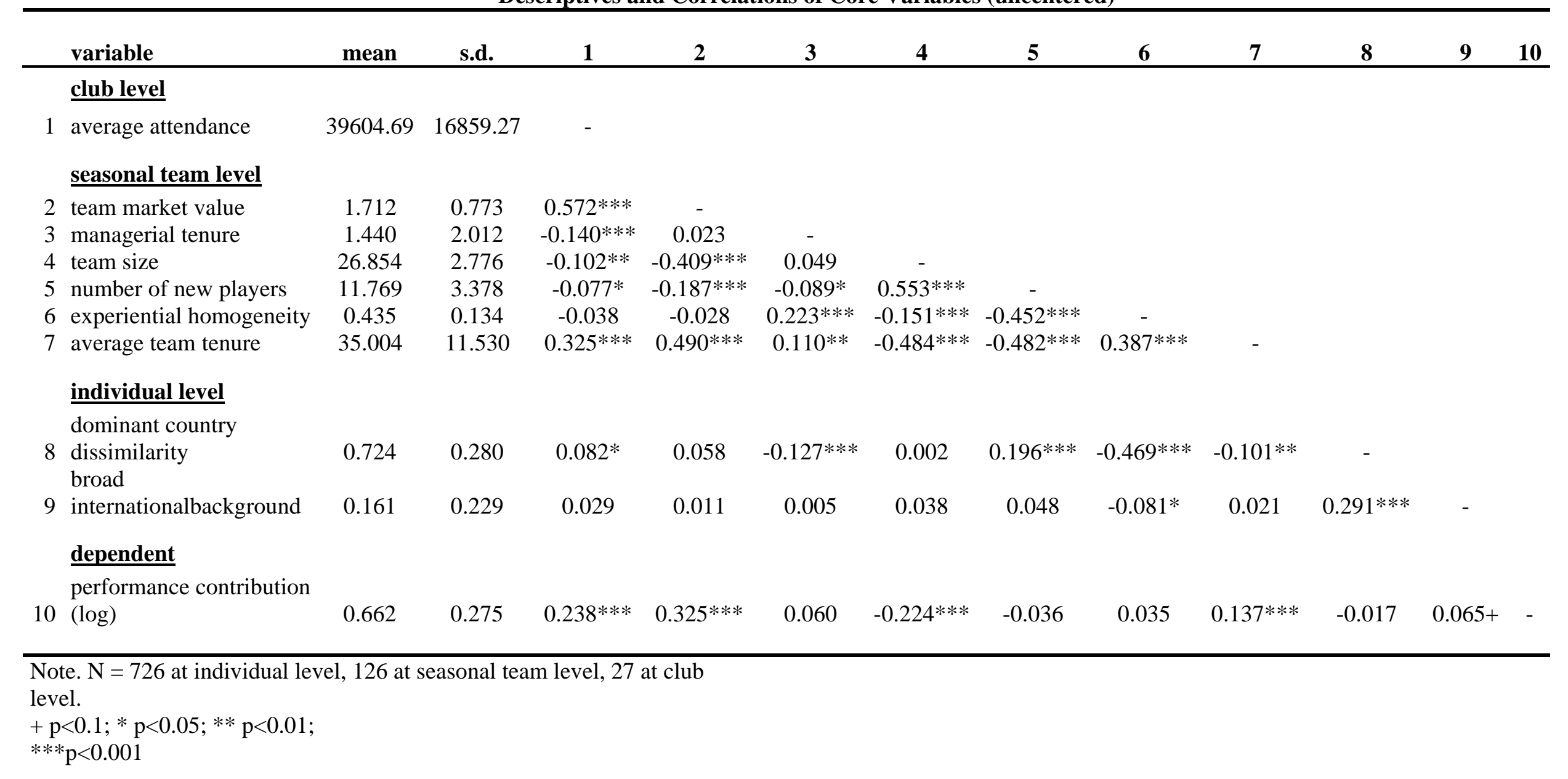


TABLE 2

Variance Decomposition

\begin{tabular}{|c|c|c|c|}
\hline nullmodel & $\begin{array}{c}\text { variance } \\
\text { decomposition } \\
(\%)\end{array}$ & $\begin{array}{c}\text { number of } \\
\text { observations }\end{array}$ & $\begin{array}{c}\text { mean } \\
\text { observations } \\
\text { per level }\end{array}$ \\
\hline $\begin{array}{c}\text { level 1 } \\
\text { (individual } \\
\text { player) }\end{array}$ & 72.573 & 726 & - \\
\hline $\begin{array}{c}\text { level 2 } \\
\text { (seasonal team) }\end{array}$ & 17.295 & 126 & 5.8 \\
\hline $\begin{array}{c}\text { level 3 } \\
\text { (club) }\end{array}$ & 10.132 & 27 & 26.9 \\
\hline significance & $\mathrm{p}<0.001$ & - & - \\
\hline
\end{tabular}


TABLE 3

Results for HLM Analysis of New Team Members' Performance Contributions (Log)

variables

intercept

club level

average

attendance

seasonal

team level

year dummies

team market value

managerial tenure

team size

number of new players

experiential homogeneity

average team tenure

\section{individual level}

defensive player (dummy)

offensive player (dummy)

dominant country

dissimilarity

broad international

background

\section{Interactions}

broad international

background *

experiential homogeneity

2.42e-06**

(9.26e-07)

(9.19e-07)

$2.48 \mathrm{e}-06^{* *}$

(9.19e-07)

2.47e-06** (9.18e-07)

model 4

$0.447 * * *$

(0.053)

$(0.053)$$$
\text { (9.18e-07) }
$$

$$
\begin{gathered}
\text { included } \\
0.068^{* *} \\
(0.022) \\
0.016^{*} \\
(0.006) \\
-0.021^{* * *} \\
(0.006) \\
0.010^{*} \\
(0.005) \\
-0.019 \\
(0.178) \\
-0.003+ \\
(0.002)
\end{gathered}
$$

included

$0.067 * *$

(0.022)

$0.016 * *$

(0.006)

$-0.021 * * *$

(0.006)

0.010 *

(0.005)

$-0.024$

(0.176)

$-0.003+$

(0.002) included

$0.067 * *$

(0.022)

$0.016 * *$

(0.006)

$-0.021 * * *$

(0.006)

0.009*

(0.005)

$-0.024$

(0.176)

$-0.003+$

(0.002) omitted

$0.262 * * *$

(0.042)

(0.043)

$-0.093 *$

$-0.096 *$

(0.040)

(0.040)

0.089*

(0.042)

(0.042)

broad international

background *

$0.014 * *$

average team tenure

Deviance: -2*e(ll)

23.50

$-17.30$

$-20.69$

$(0.005)$

Note. $\mathrm{N}=726$ at individual level, 126 at seasonal team level, 27 at club level. For variables, the first value is the HLM coefficient, and the value in parantheses is the standard error.

$+\mathrm{p}<0.1 ;{ }^{*} \mathrm{p}<0.05 ; * * \mathrm{p}<0.01 ;{ }^{* * *} \mathrm{p}<0.001$ 

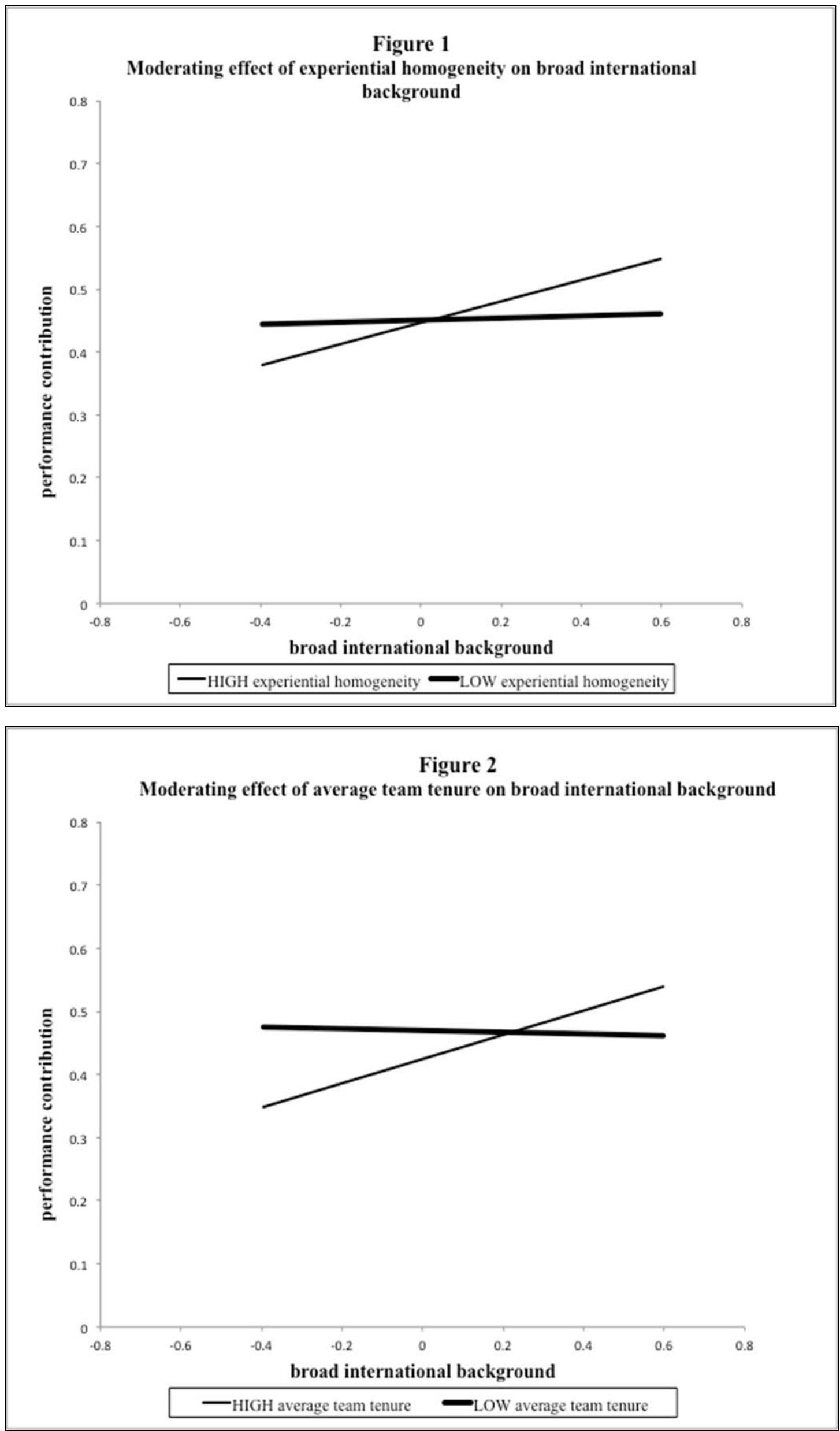